\title{
ACTN3's R577X Single Nucleotide Polymorphism Allele Distribution Differs Significantly in Professional Football Players according to Their Field Position
}

\author{
Enric Clos ${ }^{a}$ Ricard Pruna ${ }^{b}$ Matilda Lundblad ${ }^{c}$ Rosa Artells ${ }^{d}$ Nicola Maffulli ${ }^{-} \mathrm{h}$ \\ ${ }^{a}$ Girona FC Medical Services, Girona, Spain; bFC Barcelona Medical Services, FIFA Medical Centre of Excellence, \\ Barcelona, Spain; 'Sahlgrenska Academy Institute of Clinical Sciences, Gothenburg University, Gothenburg,

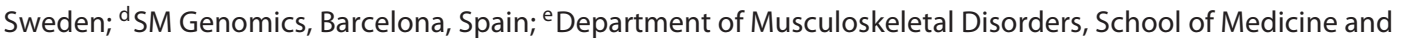 \\ Surgery, University of Salerno, Salerno, Italy; ${ }^{f}$ Clinica Ortopedica, Ospedale San Giovanni di Dio e Ruggi D'Aragona, \\ Salerno, Italy; ${ }^{9}$ Queen Mary University of London, Barts and the London School of Medicine and Dentistry, Centre \\ for Sports and Exercise Medicine, Mile End Hospital, London, UK; ${ }^{h}$ Keele University, School of Medicine, Institute of \\ Science and Technology in Medicine, Guy Hilton Research Centre, Hartshill, UK
}

\section{Significance of the Study}

- ACTN3 single nucleotide polymorphism allele distribution differs significantly according to a player's field position.

- Identifying the genetic characteristics of a player to adapt his playing position may lead to a talent orientation in young football players.

- The ACTN3 gene may be considered as a potential biomarker for performance in football.

\section{Keywords}

Single nucleotide polymorphism · Football · Genetics ·

Performance

\begin{abstract}
Introduction: Football is characterised by intermittent highintensity efforts varying according to the field position of a player. We aimed to ascertain whether polymorphisms in the ACTN3 gene are associated with different playing positions in elite professional football players. Subjects and Methods: Genotyping of the ACTN3 gene was conducted in 43 elite professional football players of a single team. Playing position was recorded based on the player's most frequent posi-
\end{abstract}

karger@karger.com www.karger.com/mpp

Karger $\stackrel{\text { ' }}{5}$

GOPEN ACCESS
(C) 2020 The Author(s)

Published by S. Karger AG, Basel

This is an Open Access article licensed under the Creative Commons Attribution-NonCommercial-4.0 International License (CC BY-NC) (http://www.karger.com/Services/OpenAccessLicense), applicable to the online version of the article only. Usage and distribution for commercial purposes requires written permission. tion. Results: The genotype distribution was not significant between positions $(p=0.057)$, while the allele distribution differed significantly $(p=0.035)$. Goalkeepers $(p=0.04, p=$ $0.03)$, central defenders $(p=0.03, p=0.01)$, and central midfielders ( $p=0.01, p=0.00$ ) had a significantly different allele distribution compared with wide midfielders and forward players. Conclusions: Genetic biomarkers may be important when analysing performance capability in elite professional football. Identifying the genetic characteristics of a player to adapt his playing position may lead to orientation of positions based on physical capabilities and tissue quality in young football players, and also to performance enhancement in those who are already playing in professional teams.

(C) 2020 The Author(s)

Published by S. Karger AG, Basel 


\section{Introduction}

The physiological demands of professional football call for the establishment of appropriate strategies for training, physical conditioning, and competition $[1,2]$ through objective quantification of the player's workload and activities [3]. The application of Global Positioning System (GPS) satellite technology has allowed the collection and processing of large volumes of data more rapidly than hand-notation Time-Motion Analysis (TMA) did in the past [2].

In football, intermittent high-intensity efforts are performed within an endurance context $[4,5]$. In a 90-min game, sprinting, jumping, kicking, turning, changing pace, and tackling take place with a high frequency [4]. TMA systems and concrete GPS technology have made it possible to characterise loads according to position on the field, offering teams the opportunity to individualise training aspects based on performance needs $[6,7]$. Central defenders (CD) and central midfielders (CM) perform sprints and high-speed running to a lesser extent than do wide midfielders (WM), fullbacks (FB) and forward players $(\mathrm{FW})$, whereas WM cover the largest distances $[6,7]$.

Performance capabilities are at least partially determined by genetics $[8,9]$. Nucleotide variations or polymorphisms may influence phenotype, and single nucleotide polymorphisms (SNPs) account for $90 \%$ of these alterations [9]. Many genes with SNPs have been associated with performance in sport, in terms of endurance capabilities, muscle strength, or training response [8].

An SNP exists in the ACTN3 gene due to a cytosine (C) to thymine $(\mathrm{T})$ transversion in position 1747 exon 16, converting an arginine (R) to a stop codon at residue 577 (R577X), thus causing 577X homozygotes to be completely deficient of the gene's encoded protein, $\alpha$-actinin 3 [10, 11]. The SNP of ACTN3 could be a potential biomarker of muscle performance, with allele 577R, more frequent in power athletes, favouring rapid and forceful muscle contraction [12-14].

The performance requirements of football players vary depending on their position on the field, and the SNP of ACTN3 is worth investigating as a potential biomarker of muscle performance. The aim of this study was to evaluate whether the genotype and allele distribution of the ACTN3 gene differs between positions on the field in elite professional football players.

\section{Subjects and Methods}

\section{Study Population}

The details of the study population have been previously described [15]. A total of 43 elite professional football players from a single club participated in the present study. The data collected included the descriptive statistics of demographic variables such as weight, height, ethnicity, age, the player's position on the field, and the allele distribution of the ACTN3 gene's polymorphism (R577X).

The position on the field was assigned according to the frequency that each player plays in each position, acknowledging that many of them are capable of playing in more than 1 position. Goalkeepers (GK), CD, FB, CM, WM, wingers (W), and FW were the categories for position on the field, as the participants belong to a team that plays a 4-3-3 formation.

\section{DNA Extraction and Genotyping}

The DNA extraction and the SNP analysis were conducted according to previous studies [15-18]. A real-time polymerase chain reaction (PCR) allelic discrimination TaqMan assay was performed. The procedure was undertaken according to the manufacturer's (Applied Biosystems, Foster City, CA, USA) instructions with minor modifications.

Approximately $4 \mathrm{~mL}$ of whole blood was extracted from each participant into EDTA vacutainer tubes and stored at $4^{\circ} \mathrm{C}$ for total DNA extraction. Genomic DNA isolation was undertaken using a QIAmp DNA Blood Minikit (Qiagen, Valencia, CA, USA), following the manufacturer's instructions. DNA quantity was measured with a Nano-Drop ND-1000 Spectrophotometer (Thermo Fisher Scientific Inc., Waltham, MA, USA). All the samples were stored at $-80^{\circ} \mathrm{C}$ until analysed.

Primers and probes were obtained from Applied Biosystems. A real-time PCR was performed on an ABI Prism 7500 Sequence Detection System (Applied Biosystems) following these conditions: $50^{\circ} \mathrm{C}$ for $2 \mathrm{~min}, 95^{\circ} \mathrm{C}$ for $10 \mathrm{~min}$, and then 40 cycles of amplification $\left(95^{\circ} \mathrm{C}\right.$ for $15 \mathrm{~s}$ and $62^{\circ} \mathrm{C}$ for $\left.1 \mathrm{~min}\right)$. For each cycle, the software measured the fluorescent signal from the VIC- or FAMlabelled probe. All PCRs were run in duplicate and contained 50 ng of DNA, $6.25 \mu \mathrm{L}$ of TaqMan Universal Master Mix (Applied Biosystems), $0.25 \mu \mathrm{L}$ of primers and probes, and water up to a final volume of $13 \mu \mathrm{L}$. Appropriate negative controls were run as well using water.

\section{Statistical Analysis}

The sample size was determined as the population in a specific professional football club, who were part of the club's first team competing in the Spanish first division during the 2007-2012 and 2015-2017 seasons. Table 1 contains the descriptive statistics of demographic variables including age, ethnicity, weight, and height [15]. Genotype frequencies were calculated and compared with HapMap data (Table 2) [15].

Genotype and allele frequencies were calculated and compared with the field position of the players (Tables 3,4 ) using a $\chi^{2}$ test. In addition, allele frequencies were compared between each individual position on the field, once again using a $\chi^{2}$ test for each of them (Table 5). All the statistical analyses were performed with SPSS version 21 for Mac. Significance was set at $p \leq 0.05$. 
Table 1. Characteristics of the study population

\begin{tabular}{lcccc}
\hline Characteristic & $\begin{array}{l}\text { Caucasian } \\
(n=23 ; 53.50 \%)\end{array}$ & $\begin{array}{l}\text { Black African } \\
(n=7 ; 16.30 \%)\end{array}$ & $\begin{array}{l}\text { Hispanic } \\
(n=13 ; 30.20 \%)\end{array}$ & $\begin{array}{l}\text { Total } \\
(n=43 ; 100 \%)\end{array}$ \\
\hline Age, years & $28.04(20-37)$ & $27.86(21-34)$ & $27.46(21-34)$ & $27.84(20-37)$ \\
Weight, kg & $74.87(65-89)$ & $75.29(69-90)$ & $74.46(62-86)$ & $74.81(62-90)$ \\
Height, cm & $179.87(170-194)$ & $179(171-191)$ & $176.15(169-186)$ & $178.61(169-194)$ \\
\hline
\end{tabular}

Table 2. Genotype frequencies in the present study and for Caucasian (HapMap CEU), Black African (HapMap YRI) and Hispanic (HapMap HISP) populations in NCBI dbSNP

\begin{tabular}{lllllllll}
\hline Gene & Genotype & Population & & & & & \\
\cline { 3 - 7 } & & $\begin{array}{l}\text { total } \\
(n=43), n(\%)\end{array}$ & $\begin{array}{l}\text { Caucasian } \\
(n=23), n(\%)\end{array}$ & $\begin{array}{l}\text { HapMap } \\
\text { CEU, } \%\end{array}$ & $\begin{array}{l}\text { Black African } \\
(n=7), n(\%)\end{array}$ & $\begin{array}{l}\text { HapMap } \\
\text { YRI, \% }\end{array}$ & $\begin{array}{l}\text { Hispanic } \\
(n=13), n(\%)\end{array}$ & $\begin{array}{l}\text { HapMap } \\
\text { HISP1, \% }\end{array}$ \\
\hline ACTN3 & $\mathrm{RR}$ & $19(44.19)$ & $9(39.13)$ & 19.46 & $5(71.43)$ & 83.19 & $6(46.15)$ & N/A \\
rs1815739 & $\mathrm{RX}$ & $21(48.84)$ & $13(56.2)$ & 58.41 & $2(28.57)$ & 16.81 & $5(38.46)$ & N/A \\
& $\mathrm{XX}$ & $3(6.97)$ & $1(4.35)$ & 22.10 & $0(0)$ & n/a & N/A \\
\hline
\end{tabular}

NCBI, National Center for Biotechnology Information; dbSNP, Single Nucleotide Polymorphism database.

Table 3. Genotype frequencies and position on the field comparison

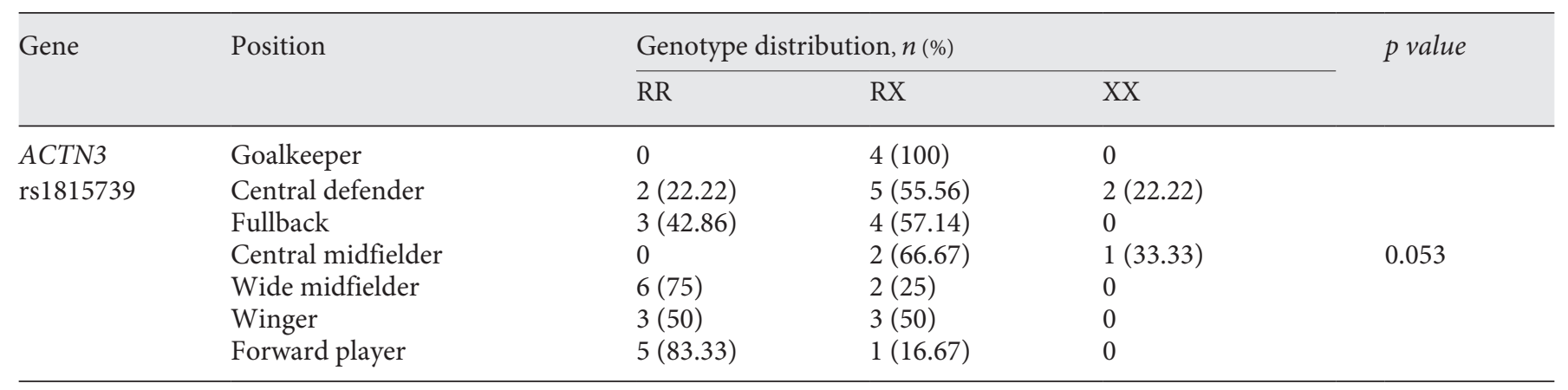

Table 4. Allele frequencies and comparison with field position

\begin{tabular}{lllll}
\hline \multirow{2}{*}{ Gene } & Position & \multicolumn{2}{l}{$\begin{array}{l}\text { Allele distribution, } \\
n(\%)\end{array}$} & \\
\cline { 3 - 4 } & & $577 \mathrm{R}$ & $577 \mathrm{X}$ \\
\hline ACTN3 & Goalkeeper & $4(50)$ & $4(50)$ & \\
rs1815739 & Central defender & $9(50)$ & $9(50)$ & \\
& Fullback & $10(71.43)$ & $4(28.57)$ \\
& Central midfielder & $2(33.33)$ & $4(66.67)$ & 0.035 \\
& Wide midfielder & $14(87.5)$ & $2(12.5)$ \\
& Winger & $9(75)$ & $3(25)$ \\
& Forward player & $11(91.67)$ & $1(8.33)$ & \\
\hline
\end{tabular}

Table 5. Comparison of field position according to allele frequencies ( $p$ values)

\begin{tabular}{lllllllll}
\hline Position & GK & CD & FB & CM & WM & W & FW \\
\hline Goalkeeper (GK) & - & ns & ns & ns & 0.04 & ns & 0.03 \\
Central defender (CD) & - & - & ns & ns & 0.03 & ns & 0.01 \\
Fullback (FB) & - & - & - & ns & ns & ns & ns \\
Central midfielder (CM) & - & - & - & - & 0.01 & ns & 0.00 \\
Wide midfielder (WM) & - & - & - & - & - & ns & ns \\
Winger (W) & - & - & - & - & - & - & ns \\
Forward player (FW) & - & - & - & - & - & - & - \\
\hline
\end{tabular}

Clos/Pruna/Lundblad/Artells/Maffulli 


\section{Results}

\section{Population}

A total of 43 professional football players from a single club participated in the study, and their demographic variables can be seen in Table 1. Most participants were Caucasians (53.50\%), followed by Hispanics (30.20\%), and Black Africans (16.30\%). The 43 players were divided into $4 \mathrm{GK}, 9 \mathrm{CD}, 7 \mathrm{FB}, 3 \mathrm{CM}, 8 \mathrm{WM}, 6 \mathrm{~W}$, and $6 \mathrm{FW}$.

Genotyping revealed that the $577 \mathrm{R}$ allele comprised 59 of the 86 alleles. A total of 19 individuals had the genotype $\mathrm{RR}, 21$ had genotype RX, and 3 had genotype XX. The allele $577 \mathrm{R}$ was present in $93 \%$ of the participants. Genotype frequencies were compared with HapMap data (Table 2).

\section{Genotype and Allele Distribution versus Position on the Field}

Genotype RX was the most prevalent overall, being present in $48.83 \%(n=21)$ of the subjects. Genotype RR was present in $44.19 \%(n=19)$ of the participants, and $6.98 \%(n=3)$ of the players had the XX genotype. In WM (75\%), W (50\%), and FW (83.33\%) the genotype RR was the most frequent, and $<50 \%$ presented the genotype RX (Table 3). Only CD and CM displayed the presence of genotype XX (22.22 and 33.33\%, respectively), while GK and CM included no individuals with genotype RR. A comparison between genotype distribution and position on the field was close to being significantly different $(p=0.057)$.

Allele $577 \mathrm{R}$ was the most prevalent, accounting for $68.60 \%$. Three positions on the field presented a distribution with a presence of $50 \%$ or less of allele $577 \mathrm{R}$, namely GK (50\%), CD (50\%), and CM (33.33\%). FW (91.67\%), WM (87.5\%), W (75\%), and FB (71.43\%), respectively, were the positions with the highest presence of allele 577R. Allele distribution differed significantly according to position on the field ( $p=0.035$ ).

When comparing each position on the field individually, GK had a different allele distribution than WM and FW ( $\mathrm{p}=0.04$ and $p=0.03)$; $\mathrm{CD}(p=0.03$ and $p=0.01)$ and $\mathrm{CM}(p=0.01$ and $p=0.00)$ showed equal differences as well.

\section{Discussion}

To our knowledge, this is the first study to evaluate the role of genetics of elite professional football players according to their specific field position. The main finding in this study was that the ACTN3 SNP distribution was not significant ( $p=0.057$ ), and that the allele distribution differed significantly $(p=0.035)$ between the positions the players have on the field. More specifically, the allele distribution of GK, CD, and $\mathrm{CM}$ differed from that of WM and FW ( $p=0.04, p=0.03 ; p=0.03, p=0.01$; and $p=0.01, p=0.00$; Table 5).

These results may be explained by the fact that the physical efforts required of the players during a match vary between different positions $[6,7,19,20]$. The genetic makeup of professional football players is different from that of the normal population [21, 22], and is also different between professional and non-professional players [22].

The ACTN3 gene has been associated with physical performance $[12-14,23,24]$. The allele $577 \mathrm{R}$ is more frequent in individuals engaged in explosive activities [12$14,23,24]$, while allele $577 \mathrm{X}$ is over-represented in subjects engaged in endurance activities $[16,25]$. In the elite professional football players involved in the present study, the heterozygous genotype RX is the most prevalent, in line with previous studies involving professional players $[15,22,26,27]$. We are aware that other studies report the opposite, where the RR genotype was more prevalent than the RX genotype [21, 28, 29]. Nevertheless, not all of them involved solely elite professional football players [21].

Football is a sport performed in an endurance context in which intermittent high-intensity efforts occur $[4,5]$. If we consider that the muscle performance of the ACTN3 gene varies between genotypes, RX individuals should generally adapt best to its physical effort requirements. RX is the most prevalent genotype among football players [15, $22,26,27]$. On the other hand, the XX genotype is much less prevalent (nearly $7 \%$ of the subjects); theoretically, this genotype would fit less well with the physical requirements of football, as it is not conducive to explosive muscle performance [12-14, 23, 24]. Further, this study is in line with previous literature in which XX individuals are less prevalent among professional players compared with the normal population $[15,21,22,26,28]$. Finally, the RR genotype is present in $44.19 \%$ of individuals and is also the most prevalent in some studies [28, 29], as it is associated with the explosive muscle performance phenotype required in football. In this respect, therefore, genetics may be a factor for football players to become professional.

Physical efforts and conditioning needs differ, depending on the position players have on the field $[6,7,19$, 20], and, as seen in this and other studies, genotype and allele distribution may also vary [25]. In a football match, $\mathrm{CM}$ and $\mathrm{CD}$ run at high speed and sprint less than WM, 
$\mathrm{FB}$, and FW [6, 7], whereas $\mathrm{CM}$ jog more than $\mathrm{FB}$ and $\mathrm{FW}$ $[6,7]$. Moreover, CD undertake the lowest high-intensity activities $[19,20]$, unlike WM and FW, who account for the highest peak game speed and frequency of high-intensity activities [19]. The allele distribution in this study shows that the explosive allele $577 \mathrm{R}$ is significantly less prevalent in $\mathrm{CD}(50 \%)$ and $\mathrm{CM}(33.33 \%)$ than in WM $(87.5 \%)$ and FW (91.67\%; $p=0.03, p=0.01$ and $p=0.01$, $p=0.00$; Table 4). Further, the XX genotype is only present in CD and CM (Table 3). These results are therefore consistent with the positional physical efforts described in the literature $[6,7,19,20]$. Again, genetics may play a role for a player to reach professional level.

The RX genotype has been considered to be protective of soft-tissue musculoskeletal injury susceptibility in professional football [15], whereas genotype XX has been associated with a greater risk of injury [15]. The previous explanation of physical demands in football according to the field position and its association with genetic makeup agrees with the results of these injury studies, as genotype $\mathrm{RX}$, which adapts most effectively to the demands in football, is the one with the lowest injury prevalence. On the other hand, genotype XX, which may be less suited to football, is associated with the highest odds of injury.

We are aware of the limitations of this study. First, all the players belong to a single club in which the 4-3-3 formation is used as the main tactic. Football matches differ in terms of demands and results. In addition, teams use different tactics and formations on the field based on a manager's considerations and decisions. Moreover, physical training, the environment, season schedule, and ergonomic aids may vary between teams. It is not possible to consider all of these factors when associations between genotype and performance are undertaken. Finally, each player was classified according to the main position of play. However, as we pointed out, some players played in several positions, according to the tactical needs of the team. We are aware that this may have introduced a degree of uncertainty, but this is inevitable given the needs of a modern football team. As seen in Results, in some instances a playing position was not connected to a specific allele distribution.

Ideally, it would be interesting to be able to introduce as control a phenotype/genotype of a gene that is not thought to exert any influence on physical performance to make sure that there were no differences in this according to player position. This should be the basis for future endeavours in this field.

The results of the present study could provide clubs with a tool for talent orientation in young players, and guide performance enhancement training in professional players already performing at elite level. When these findings are combined with the fact that the ACTN3 gene has been shown to be a factor in soft-tissue musculoskeletal injuries incidence [15], it could also produce a reduction in injuries if players adapt their position on the field to match its genetic profiles. Thus, this study contributes to the endorsement of predictive genomics DNA profiling described in the past as a tool to be used by professional football clubs in order to establish a genetic-based targeted training [30]. Detecting abilities and weaknesses in association with sports performance can lead to individualised training programs, prevention protocols, and nutrition aids [30].

\section{Conclusions}

The recent literature on genetics in professional football suggests potential biomarkers of injury susceptibility and performance. This study suggests that the ACTN3 SNP gene may be a suitable biomarker for orientation of field position and performance enhancement, as physical capabilities and tissue quality vary among genotypes. Individualisation should be considered when assessing professional players and football teams in terms of performance enhancement and injury prevention.

\section{Acknowledgements}

We thank FC Barcelona Medical Services for all the provided data. We also thank Miquel Serrado for contributing his knowledge of football to this study.

\section{Statement of Ethics}

This study was approved by the Ethics Committee of Universitat de Barcelona, Barcelona, Spain (Registry No. IBR00003099). All the football players were fully informed in writing about the procedures of the study, and they gave their signed informed consent to participate.

\section{Conflict of Interest Statement}

The authors have no conflicts of interest to declare.

\section{Funding Sources}

The article was funded by the authors themselves. 


\section{References}

1 Carling C, Bloomfield J, Nelsen L, Reilly T. The Role of Motion Analysis in Elite Soccer: Contemporary Performance Measurement Techniques and Work Rate Data. Sports Med. 2008;38(10):839-62.

2 Johnston RJ, Watsford ML, Pine MJ, Spurrs RW, Murphy AJ, Pruyn EC. The validity and reliability of $5-\mathrm{Hz}$ global positioning system units to measure team sport movement demands. J Strength Cond Res. 2012 Mar;26(3): 758-65.

3 Dalen T, Ingebrigtsen J, Ettema G, Hjelde $\mathrm{GH}$, Wisløff U. Player load, acceleration, and deceleration during forty-five competitive matches of elite soccer. J Strength Cond Res. 2016 Feb;30(2):351-9.

4 Stølen T, Chamari K, Castagna C, Wisløff U. Physiology of soccer: an update. Sports Med. 2005;35(6):501-36.

5 Taylor JB, Wright AA, Dischiavi SL, Townsend MA, Marmon AR. Activity demands during multi-directional team sports: A Systematic Review. Sports Med. 2017 Dec; 47(12):2533-51.

6 Tierney PJ, Young A, Clarke ND, Duncan MJ. Match play demands of 11 versus 11 professional football using Global Positioning System tracking: variations across common playing formations. Hum Mov Sci. 2016 Oct;49: $1-8$.

7 Torreño N, Munguía-Izquierdo D, Coutts A, de Villarreal ES, Asian-Clemente J, SuarezArrones L. Relationship Between External and Internal Loads of Professional Soccer Players During Full Matches in Official Games Using Global Positioning Systems and Heart-Rate Technology. Int J Physiol Perform. 2016;11(7):940-6.

8 Sarzynski MA, Loos RJ, Lucia A, Pérusse L, Roth SM, Wolfarth B, et al. Advances in exercise, fitness, and performance genomics in 2015. Med Sci Sports Exerc. 2016 Oct;48(10): 1906-16.

9 Pruna R, Clos E, Bahdur K, Artells R. Influence of genetics on sports injuries. J Nov Physiother. 2017;07(04)

10 North K. Why is alpha-actinin-3 deficiency so common in the general population? The evolution of athletic performance. Twin Res Hum Genet. 2008 Aug;11(4):384-94.
11 Mills M, Yang N, Weinberger R, Vander Woude DL, Beggs AH, Easteal S, et al. Differential expression of the actin-binding proteins, alpha-actinin-2 and -3 , in different species: implications for the evolution of functional redundancy. Hum Mol Genet. 2001 Jun;10(13):1335-46.

12 Pimenta EM, Coelho DB, Veneroso CE, Barros Coelho EJ, Cruz IR, Morandi RF, et al. Effect of ACTN3 gene on strength and endurance in soccer players. J Strength Cond Res. 2013 Dec;27(12):3286-92.

13 Weyerstraß J, Stewart K, Wesselius A, Zeegers M. Nine genetic polymorphisms associated with power athlete status - A Meta-Analysis. J Sci Med Sport. 2018 Feb;21(2):213-20.

14 Wilson GC, Mavros Y, Tajouri L, Singh MF Activity P, Faculty W, et al. The role of genetic profile in functional performance adaptations to exercise training or physical activity: A systematic review of the literature. J Aging Phys Act. 2019 Aug;27(4):594-616.

15 Clos E, Pruna R, Lundblad M, Artells R, Esquirol Caussa J. ACTN3 single nucleotide polymorphism is associated with non-contact musculoskeletal soft-tissue injury incidence in elite professional football players. Knee Surg Sports Traumatol Arthrosc. 2019 Dec; 27(12):4055-61.

16 Pruna R, Artells R, Lundblad M, Maffulli N. Genetic biomarkers in non-contact muscle injuries in elite soccer players. Knee Surg Sports Traumatol Arthrosc. 2017 Oct;25(10): 3311-8.

17 Pruna R, Artells R, Ribas J, Montoro B, Cos F, Muñoz C, et al. Single nucleotide polymorphisms associated with non-contact soft tissue injuries in elite professional soccer players: influence on degree of injury and recovery time. BMC Musculoskelet Disord. 2013 Jul; 14(1):221

18 Pruna R, Ribas J, Montoro JB, Artells R. The impact of single nucleotide polymorphisms on patterns of non-contact musculoskeletal soft tissue injuries in a football player population according to ethnicity. Med Clin (Barc). 2015 Feb;144(3):105-10

19 Palucci Vieira LH, Carling C, Barbieri FA, Aquino R, Pereira Santiago PR. Match running performance in young soccer players: A systematic review. Sports Med. 2019 Feb; 49(2):289-318.

20 Metaxas TI. Match running performance of elite soccer players: V[Combining Dot Above $\mathrm{O} 2 \mathrm{max}$ and players position influence. J Strength Cond Res. 2018, Online ahead of print.
21 Egorova ES, Borisova AV, Mustafina LJ, Arkhipova AA, Gabbasov RT, Druzhevskaya AM, et al. The polygenic profile of Russian football players. J Sports Sci. 2014;32(13): 1286-93.

22 Coelho DB, Pimenta EM, Rosse IC, de Castro BM, Becker LK, de Oliveira EC, et al. Evidence for a role of ACTN3 R577X polymorphism in football player's career progression. Int $\mathrm{J}$ Sports Med. 2018 Dec;39(14):1088-93.

23 MacArthur DG, North KN. A gene for speed? The evolution and function of alpha-actinin-3. BioEssays. 2004 Jul;26(7):786-95.

24 Yang N, MacArthur DG, Gulbin JP, Hahn AG, Beggs AH, Easteal S, et al. ACTN3 genotype is associated with human elite athletic performance. Am J Hum Genet. 2003 Sep; 73(3):627-31.

25 Massidda M, Mendez-Villanueva A, Ginevičienè $V$, Proia $P$, Drozdovska SB, Dosenko V, et al. Association of Monocarboxylate Transporter-1 (MCT1) A1470T Polymorphism (rs1049434) With Forward Football Player Status . Int J Sports Med. 2018;39(13):1028-34.

26 Massidda M, Scorcu M, Calò CM. New genetic model for predicting phenotype traits in sports. Int J Sports Physiol Perform. 2014 May;9(3):554-60.

27 Dionísio TJ, Thiengo CR, Brozoski DT, Dionísio EJ, Talamoni GA, Silva RB, et al. The influence of genetic polymorphisms on performance and cardiac and hemodynamic parameters among Brazilian soccer players. Appl Physiol Nutr Metab. 2017 Jun;42(6):596-604.

28 Galeandro V, Notarnicola A, Bianco A, Tafuri S, Russo L, Pesce V, et al. ACTN3/ACE genotypes and mitochondrial genome in professional soccer players' performance. J Biol Regul Homeost Agents. 2017 Jan-Mar;31(1): 207-13.

29 Pimenta EM, Coelho DB, Cruz IR, Morandi RF, Veneroso CE, de Azambuja Pussieldi G. et al. The ACTN3 genotype in soccer players in response to acute eccentric training. Eur J Appl Physiol. 2012 Apr;112(4):1495-503.

30 Kambouris M, Del Buono A, Maffulli N. Genomics DNA profiling in elite professional soccer players: a pilot study. Transl Med UniSa. 2014 Apr;9:18-22. 